Каира Юрий Владимирович

кандидат социологических наук, доцент, доцент кафедры социологии и информационных технологий Среднерусского института управления Российской академии народного хозяйства и государственной службы при Президенте РФ

\section{КЛАССИФИКАЦИЯ НАСЕЛЕНИЯ ОРЛОВСКОЙ ОБЛАСТИ ПО УРОВНЮ СОЦИАЛЬНОЙ НАПРЯЖЕННОСТИ МЕТОДОМ КЛАСТЕРНОГО АНАЛИЗА}

Аннотация:

В работе представлено описание процедуры кластерного анализа для классификации населения Орловской области по уровню социальной напряженности. Выявлены следующие кластеры: «отрицающие публичный протест», шактивные оппозиционеры", «инертные недовольные», "пассивные пессимисты», «благополучные консерваторы", "латентные оппозиционеры». Дано подробное описание представителей всех шести кластеров. В результате проведенного анализа выявлены два кластера (латентные и активные оппозиционеры) с повышенным уровнем социальной напряженности, представители которых ө той или иной мере выразили готовность принять участие в акциях массового протеста. Предложены меры по снижению уровня социальной напряженности в исследуемом регионе, такие как решение социально-экономических проблем, проблем в сфрере ЖКХ, популяризация действий властей через средства массовой информации.

Ключевые слова:

социальная напряженность, кластерный анализ, семантический анализ, материальное положение социальное самочувствие, протестная активность, акции массового протеста, социально-экономическая ситуация, политическая обстановка, население Орловской области.
Kaira Yury Vladimirovich

PhD in Social Science, Associate Professor, Social Science and Information Technologies Department, Central Russian Institute of Management Russian Presidential Academy of

National Economy and Public Administration

\section{THE CLASSIFICATION OF POPULATION IN ORYOL REGION ACCORDING TO THE DEGREE OF SOCIAL TENSION BY MEANS OF CLUSTER ANALYSIS}

Summary:

The article describes the method of cluster analysis applied to classify the population of Oryol region according to the degree of social tension. The study reveals the following clusters: "people denying the public protest", "active oppositionists", "inert dissatisfied people", "passive pessimists", "prosperous conservatives", and "Iatent oppositionists". The paper describes the representatives of these six clusters in detail. Based on the analysis results, the author identifies two clusters (latent and active oppositionists) with the high degree of social tension where the representatives are ready to participate in mass protest rallies to some extent. The article provides measures to reduce social tension in the region under review. They include the solution of social, economic and public utility problems, the promotion of authority actions through mass media.

Keywords: social tension, cluster analysis, semantic analysis, financial situation, social well-being, protest activity, mass protest rallies, social and economic situation, political situation, population of Oryol region.

Социальная напряженность представляет собой негативное эмоциональное состояние, характерное для определенной группы людей. Данное состояние обусловливается существованием на протяжении достаточно продолжительного времени неразрешаемой ситуации рассогласования между социальными ожиданиями, интересами, потребностями всего населения или его значительной части и их фрактическим удовлетворением [1].

Для анализа социальной напряженности в Орловской области на кафедре социологии и психологии управления Российской академии народного хозяйства и государственной службы при Президенте РФ в 2014 г. было проведено исследование «Социальная напряженность в регионе». Объем выборочной совокупности составил 1300 респондентов.

Социальная напряженность проявляется по-разному: от молчаливого недовольства до массовых выступлений населения, митингов, протестных акций. Для классификации населения Орловской области по уровню социальной напряженности и протестной активности был использован метод кластеризации. Этот метод представляет собой многомерную статистическую процедуру, с помощью которой выполняется кластерный анализ. Он производится в несколько этапов:

- определение выборки для проведения процедуры кластеризации;

- установление ряда переменных, на основе которых будет проводиться анализ;

- создание социальных групп (кластеров) сходных по своим параметрам объектов [2]. 
Метод кластеризации дает возможность выявлять модели поведения населения определенных социальных групп при повышении/понижении социальной напряженности [3]. Из исследуемой базы данных отобраны переменные, которые характеризуют определенные проявления социальной напряженности (таблица 1).

\section{Таблица 1 - Характеристика переменных кластерного анализа}

\begin{tabular}{|c|c|c|}
\hline Вопросы анкеты & Варианты ответов респондентов & $\begin{array}{c}\text { Проявления социальной } \\
\text { напряженности, которые } \\
\text { характеризуются } \\
\text { переменной } \\
\end{array}$ \\
\hline $\begin{array}{l}\text { В какой степени Вы удовлетворены } \\
\text { экономическим и социальным поло- } \\
\text { жением в регионе? }\end{array}$ & $\begin{array}{l}\text { 1) полностью удовлетворен (-а); } \\
\text { 2) скорее удовлетворен (-а), чем не- } \\
\text { удовлетворен; } \\
\text { 3) скорее неудовлетворен (-а), чем } \\
\text { удовлетворен; } \\
\text { 4) полностью неудовлетворен (-а) }\end{array}$ & \multirow{2}{*}{$\begin{array}{l}\text { степень удовлетворенно- } \\
\text { сти экономической и соци- } \\
\text { альной обстановкой и пер- } \\
\text { спективами ее дальней- } \\
\text { шего развития }\end{array}$} \\
\hline $\begin{array}{l}\text { Как Вы оцениваете политическую об- } \\
\text { становку в стране? }\end{array}$ & $\begin{array}{l}\text { 1) благополучная; } \\
\text { 2) спокойная; } \\
\text { 3) умеренно напряженная; } \\
\text { 4) взрывоопасная, крайне напряженная }\end{array}$ & \\
\hline $\begin{array}{l}\text { Какое определение больше всего } \\
\text { подходит для описания происходя- } \\
\text { щего в настоящий момент в России? }\end{array}$ & $\begin{array}{l}\text { 1) стабильное положение; } \\
\text { 2) временные трудности; } \\
\text { 3) усиление стагнации; } \\
\text { 4) нарастание кризисной ситуации; } \\
\text { 5) увеличение беспорядков, хаоса; } \\
\text { 6) становление жесткой диктатуры, ре- } \\
\text { прессии }\end{array}$ & $\begin{array}{l}\text { оценка происходящего } \\
\text { данный момент в России }\end{array}$ \\
\hline $\begin{array}{l}\text { Должно ли население обладать пра- } \\
\text { вом публичного выражения своей не- } \\
\text { удовлетворенности существующим } \\
\text { положением дел в стране? }\end{array}$ & $\begin{array}{l}\text { 1) определенно да; } \\
\text { 2) скорее да; } \\
\text { 3) скорее нет; } \\
\text { 4) определенно нет } \\
\end{array}$ & \multirow{2}{*}{$\begin{array}{ll}\text { причины } & \text { и вероятность } \\
\text { массовых } & \text { протестных вы- } \\
\text { ступлений } & \end{array}$} \\
\hline $\begin{array}{l}\text { Как Вы считаете, возможны ли в } \\
\text { настоящий момент массовые про- } \\
\text { тестные выступления в регионе? }\end{array}$ & $\begin{array}{l}\text { 1) да; } \\
\text { 2) нет }\end{array}$ & \\
\hline $\begin{array}{l}\text { Примете ли Вы личное участие в мас- } \\
\text { совых протестных выступлениях, } \\
\text { если они состоятся? }\end{array}$ & $\begin{array}{l}\text { 1) да, приму личное участие; } \\
\text { 2) приму личное участие при опреде- } \\
\text { ленных обстоятельствах; } \\
\text { 3) не буду принимать участия } \\
\end{array}$ & $\begin{array}{l}\text { готовность личного участия } \\
\text { в массовых протестных вы- } \\
\text { ступлениях }\end{array}$ \\
\hline $\begin{array}{l}\text { По Вашему мнению, могут ли выступ- } \\
\text { ления населения против деятельно- } \\
\text { сти властей каким-то образом улуч- } \\
\text { шить существующую ситуацию? }\end{array}$ & $\begin{array}{l}\text { 1) да, конечно; } \\
\text { 2) скорее да, чем нет; } \\
\text { 3) скорее нет, чем да; } \\
\text { 4) нет }\end{array}$ & $\begin{array}{l}\text { оценка эффрективности про- } \\
\text { тестных мероприятий и } \\
\text { массовых выступлений }\end{array}$ \\
\hline
\end{tabular}

Кластеры получили названия по их основным характеристикам. При этом были проинтерпретированы семантически укрупненные характеристики кластеров [4]. В результате они получили название в соответствии с характеристиками их основных представителей (рисунок 1).

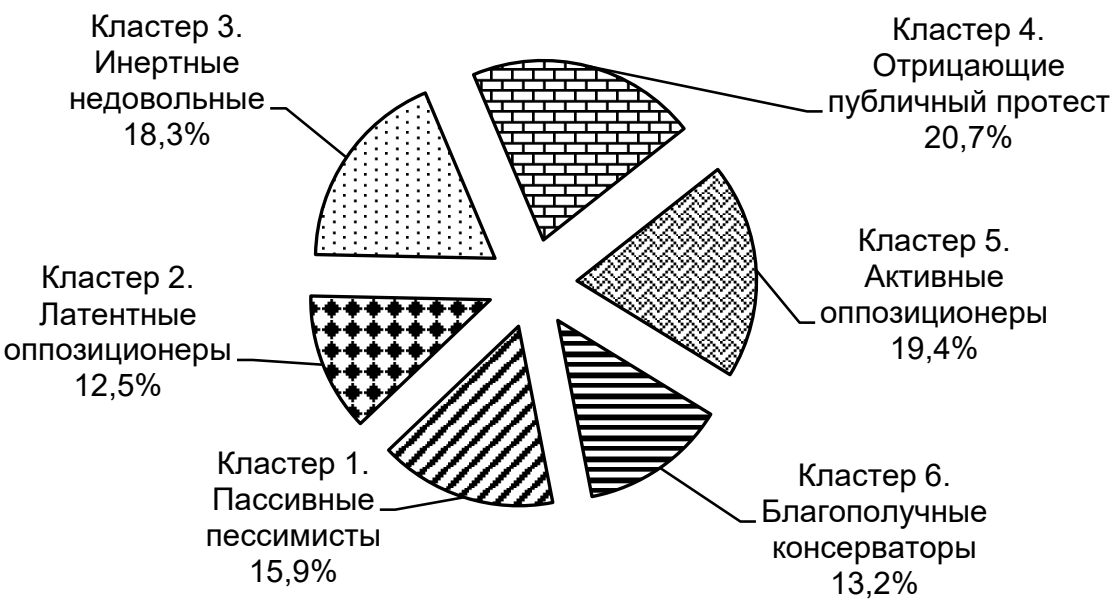

Рисунок 1 - Классификация жителей Орловской области по протестному потенциалу 


\section{Пассивные пессимисты.}

Основные характеристики: тельная;

- полагают, что экономическая и социальная обстановка в области скорее неудовлетвори-

- считают, что Россия находится в ситуации, близкой к кризисной;

- придерживаются мнения, что люди должны обладать правом публичного выражения собственной позиции и своего отношения к политике, проводимой действующей властью;

- выражают точку зрения, что протестные выступления в регионе невозможны. Если такие выступления состоятся, то большинство представителей кластера не будут в них участвовать;

- среди причин, по которым смогут принять участие в массовых выступлениях против действий властей, выделяют «беспредел представителей властвующих структур», «затронет здоровье или безопасность членов семьи»;

- уверены, что протестные выступления против деятельности властей не могут оказать влияния на решение проблем.

В половозрастной структуре первого кластера преобладают мужчины всех возрастных категорий, за исключением категории 30-44 лет. В данной возрастной категории, напротив, отмечается преобладание населения женского пола. Средний возраст представителей кластера - 45 лет. Уровень дохода составляет 10 тыс. р. ежемесячно на каждого члена семьи. По роду деятельности характерна значительная доля пенсионеров и чиновников. Представители кластера не имеют ярко выраженной географической локализации, распределены по всем типам поселений равномерно.

\section{Латентные оппозиционеры}

Основные характеристики:

- полагают, что экономическая и социальная обстановка в области в значительной степени неудовлетворительная;

- считают, что Россия находится в ситуации, близкой к кризисной;

- придерживаются мнения, что люди должны обладать правом публичного выражения собственной позиции и своего отношения к политике, проводимой действующей властью;

- выражают точку зрения, что протестные выступления в регионе невозможны. Если такие выступления состоятся, то большинство представителей кластера будут в них участвовать;

- уверены, что протестные выступления против деятельности властей могут оказать влияние на решение ряда проблем.

В половозрастной структуре второго кластера преобладают мужчины всех возрастных категорий, за исключением категории 45-59 лет. В данной возрастной категории, напротив, отмечается преобладание населения женского пола. Средний возраст представителей кластера 41 год. Уровень дохода составляет 9 тыс. р. ежемесячно на каждого члена семьи. По роду деятельности значительную часть кластера составляют занятые в сфере транспорта и связи, представители финансово-кредитных организаций и учреждений, студенческая молодежь. По месту проживания преобладают представители сельских поселений.

\section{Инертные недовольные.}

Основные характеристики:

- полагают, что социально-экономическая обстановка в области скорее неудовлетворительная;

- считают, что Россия находится в ситуации, близкой к кризисной;

- придерживаются мнения, что люди должны обладать правом публичного выражения собственной позиции и своего отношения к политике, проводимой действующей властью;

- выражают точку зрения, что протестные выступления в регионе возможны. Если такие выступления состоятся, то большинство представителей кластера не будут в них участвовать;

- среди причин, по которым они смогут участвовать в выступлениях, выделяют: «денежное вознаграждение», «если ситуация станет совсем безысходной», в том случае если данные выступления будут «законными и безопасными»;

- уверены, что протестные выступления против деятельности властей не могут оказать влияния на решение проблем.

В половозрастной структуре третьего кластера преобладают женщины различных возрастных категорий, за исключением самой старшей категории. В данной возрастной категории, напротив, отмечается преобладание населения мужского пола. Средний возраст представителей кластера - 39 лет. Уровень дохода составляет 10 тыс. р. ежемесячно на каждого члена семьи. По роду деятельности значительную часть кластера составляют занятые в сфере торговли, бытового обслуживания, в сельском хозяйстве. Представители кластера не имеют ярко выраженной географической локализации, распределены по всем типам поселений равномерно.

Отрицающие публичный протест.

Основные характеристики:

- полностью не удовлетворены социально-экономической обстановкой в регионе; 
- считают, что Россия находится в стагнации;

- придерживаются мнения, что население не всегда имеет право публично выражать собственную позицию и свое отношение к политике, проводимой действующей властью;

- выражают точку зрения, что протестные выступления в регионе невозможны. Если такие выступления состоятся, то большинство представителей кластера не будут в них участвовать;

- среди причин, по которым они смогут участвовать в выступлениях, выделяют: «денежное вознаграждение», «если ситуация станет совсем безысходной», «если заставит руководство»;

- уверены, что акции массового протеста бесполезны.

В половозрастной структуре четвертого кластера практически отсутствуют гендерные различия. Средний возраст представителей кластера - 42 года. Уровень дохода составляет 9,5 тыс. p. ежемесячно на каждого члена семьи. По роду деятельности значительную часть кластера составляют работники науки, образования, здравоохранения, культуры. Также в состав кластера входят военные и сотрудники органов правопорядка. Преобладают жители города Орла.

\section{Активные оппозиционеры.}

Основные характеристики:

- полностью не удовлетворены социально-экономической обстановкой в регионе;

- считают, что Россия находится в ситуации, близкой к кризисной;

- придерживаются мнения, что люди должны обладать правом публичного выражения собственной позиции и своего отношения к политике, проводимой действующей властью;

- выражают точку зрения, что в регионе возможны выступления против действия властей. Если они состоятся, большинство представителей кластера будут принимать в них участие;

- причинами участия в выступлениях против деятельности властей оставшееся население называет «массовый характер данных выступлений» и «соответствующую поддержку СМИ»;

- уверены, что выступления против деятельности властей могут в значительной степени повлиять на решение ряда проблем и стать механизмом взаимодействия власти и населения.

В половозрастной структуре пятого кластера преобладают женщины, но доля мужчин с увеличением возраста растет, в последней возрастной категории они преобладают. Средний возраст представителей кластера - 43 года. Уровень дохода составляет 9 тыс. р. ежемесячно на каждого члена семьи. По роду деятельности значительную часть данного кластера составляют безработные. По месту проживания преобладают жители сельской местности.

\section{Благополучные консерваторы.}

Основные характеристики:

- полностью удовлетворены социально-экономической обстановкой в регионе; нениями;

- считают, что Россия находится в ситуации стабильного развития с временными затруд-

- придерживаются мнения, что население лишь в редких случаях имеет право публично выражать собственную позицию и свое отношение к политике, проводимой действующей властью;

- выражают точку зрения, что протестные выступления в регионе невозможны. Если такие выступления состоятся, то большинство представителей кластера не будут в них участвовать;

- уверены, что акции массового протеста бесполезны.

В половозрастной структуре шестого кластера преобладают мужчины, кроме самой последней возрастной категории. Третью часть представителей данного кластера составили мужчины в возрасте 30-44 лет. Средний возраст представителей кластера - 41 год. Уровень дохода составляет 13,5 тыс. р. ежемесячно на каждого члена семьи. По роду деятельности значительную часть кластера составляют занятые в промышленной сфрере. По месту проживания преобладают жители города Орла и малых городов региона [5].

В результате проведенного анализа были выявлены кластеры, представители которых готовы участвовать в выступлениях против деятельности властей. Общая численность представителей данных кластеров составила почти треть населения области (старше 18 лет). В составе данных кластеров преобладают жители сельских поселений, население областного центра составляет меньшинство. Они характеризуются низким материальным уровнем, но предъявляют повышенные запросы. Для активации данных кластеров не хватает ядра протестного движения, лидеров, которые не удовлетворены существующим положением дел и готовы выступить с акциями массового протеста, так как верят, что они способны изменить ситуацию. Данного кластера в процессе анализа выявлено не было. Таким образом, пока такая социальная группа не будет сформирована и институционализирована формальным или неформальным образом, выступления населения против деятельности властей в регионе маловероятны.

Чтобы снизить социальную напряженность в регионе, необходимо действовать в следующих направлениях: изменение социально-экономической ситуации, создание рабочих мест, серьезное реформирование сферы ЖКХ. Больше всего нуждаются в данных изменениях жители 
сельских населенных пунктов. Также следует популяризировать действия представителей властных структур с помощью СМИ, так как население, входящее в состав второго кластера (готовое к участию в акциях массового протеста), в качестве одной из причин своей готовности назвало именно бездействие властных структур.

\section{Ссылки:}

1. Wright Q. The Escalation of International Conflicts // Journal of Conflict Resolution. 1965. Vol. 9. P. 434-449.

2. Галицкая Е.Г., Галицкий Е.Б. Деревья классификации // Социологические исследования. 2013. № 3. С. 84-88.

3. Шубат О.М., Караева А.П. Кластерный анализ в исследовании социально-экономических процессов: опыт критического анализа // Проблемы моделирования социальных процессов: Россия и страны ATP : материалы II Всерос. науч.-практ. конф. с междунар. участием. Владивосток, 2016. С. 325-328.

4. Алексеенок А.А., Бараночников В.А. Методика классификации населения региона по протестному потенциалу // Фундаментальные исследования. 2013. № 10-9. С. 2090-2094.

5. Алексеенок А.А., Каира Ю.В., Бараночников В.А. Социальное неравенство и социальная напряженность : монография. Орел, 2016. 244 с. 